\title{
ANAESTHESIA FOR CARDIOPULMONARY BYPASS IN CALVES
}

John K. MacFardane, M.D., C.M., M.sc., F. A. RoBmlard, M.D., C.M., AND

P. E. BLUNDELL, M.D., F.R.C.s.(C)*

THE INCREASING USE OF CALVES in cardiovascular surgical research is prompted by several factors. These animals appear to tolerate long periods of cardiopulmonary bypass better than dogs, and postoperative haemorrhage is seldom a problem. The size of the heart in a four- to six-week-old calf compares with that of a human of similar weight. The animals are easily procured and their care is relatively simple.

In animal experimentation it is essential to have an efficient method of anaesthesia which is both safe and easy to administer. Conventional barbiturate anaesthesia is poorly tolerated in calves, ${ }^{1,2}$ thus inhalation methods have been used. Although Larson et al. described such a technique in 1963, ${ }^{1}$ we have found no recent reports on the use of newer inhalation agents in cardiopulmonary bypass procedures in calves. A method has been developed in the University Surgical Clinic of the Montreal General Hospital which has proven simple and reproducible in a series of aortic valve replacements in calves.

\section{METHOD}

The animals are ideally three to six weeks old and weigh 40 to $60 \mathrm{kgs}$. They are brought to hospital three days before the procedure and are fasted from the twelfth preoperative hour.

Forty-five minutes before induction they are premedicated with $0.6 \mathrm{mg}$. atropine sulphate intramuscularly. Induction is begun using succinylcholine chloride ( $1 \mathrm{mg} . / 5 \mathrm{lbs}$. body weight) intramuscularly in the neck region. The paralysed animal is placed supine on a table where ventilation with 100 per cent oxygen for one or two minutes is carried out with an adapted respirator bag (Fig. 1). The foot of the table is raised to prevent aspiration of ruminal contents before intubation.

Intubation is performed with a cuffed g' tygon endotrachael tube ( $20^{\prime \prime}$ long, ж/" I.D., Fig. 2) using a long-arm laryngoscope. The cuff is inflated and ventilation is-begun using a compressed oxygen-driven standard laboratory respirator. Fifteen breaths per minute are delivered at an inspiration-expiration ratio of 1:3. Airway pressure is measured via a side arm in the endotracheal tube and maintained at $15-18 \mathrm{~mm}$. Hg. A Levin tube is passed to decompress the rumen.

Methoxyflurane (Penthrane) is administered through a Pentec vaporizer in the inspiratory line (Fig. 3). An initial concentration of 1 per cent is used while the animal is shaved and washed. The level is decreased to 0.5 per cent after skin incisions have been completed.

-McGill University Surgical Clinic, Montreal General Hospital, Montreal, P.Q. 


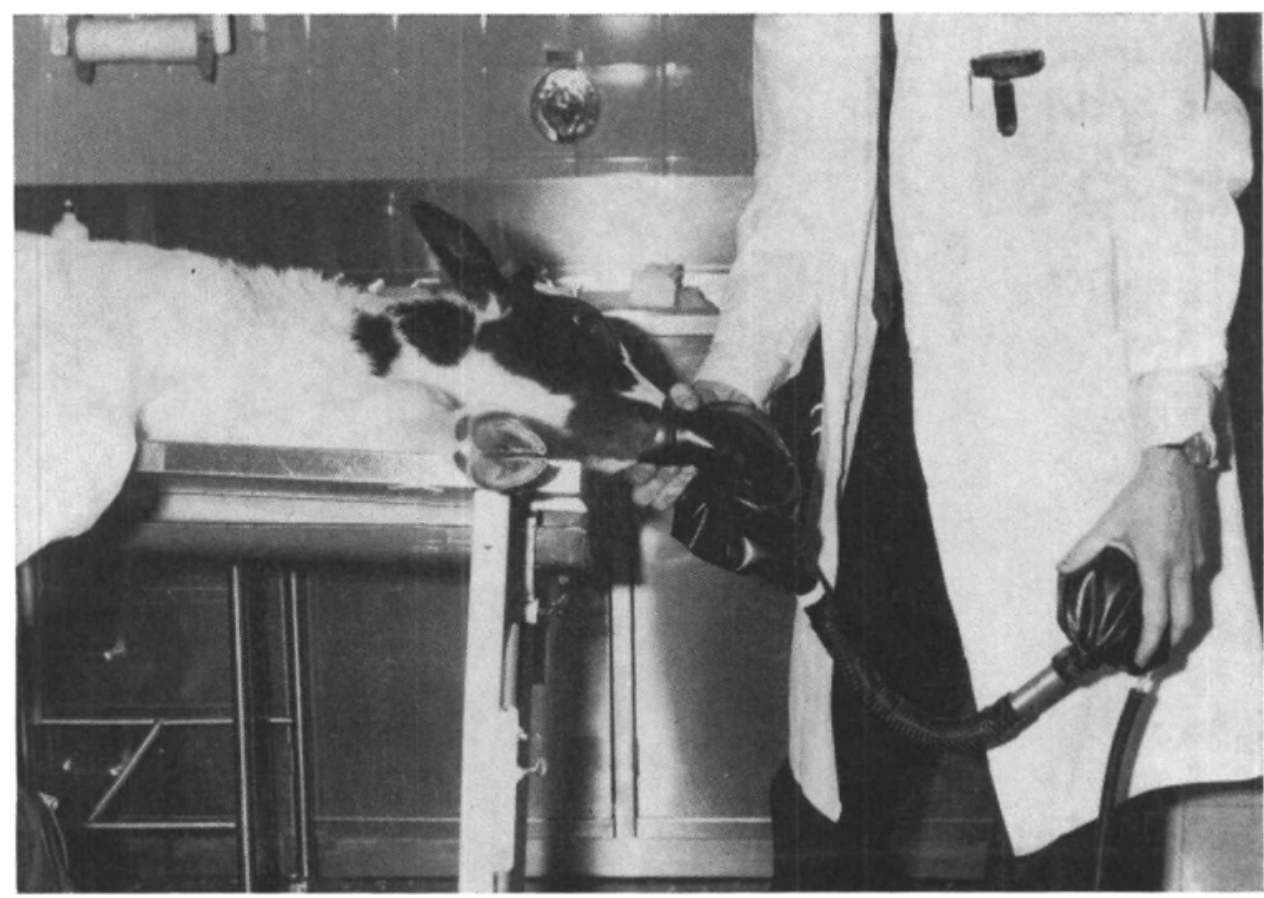

Freure 1. Ventilating the calf in the induction room. Note that the foot of table is raised.

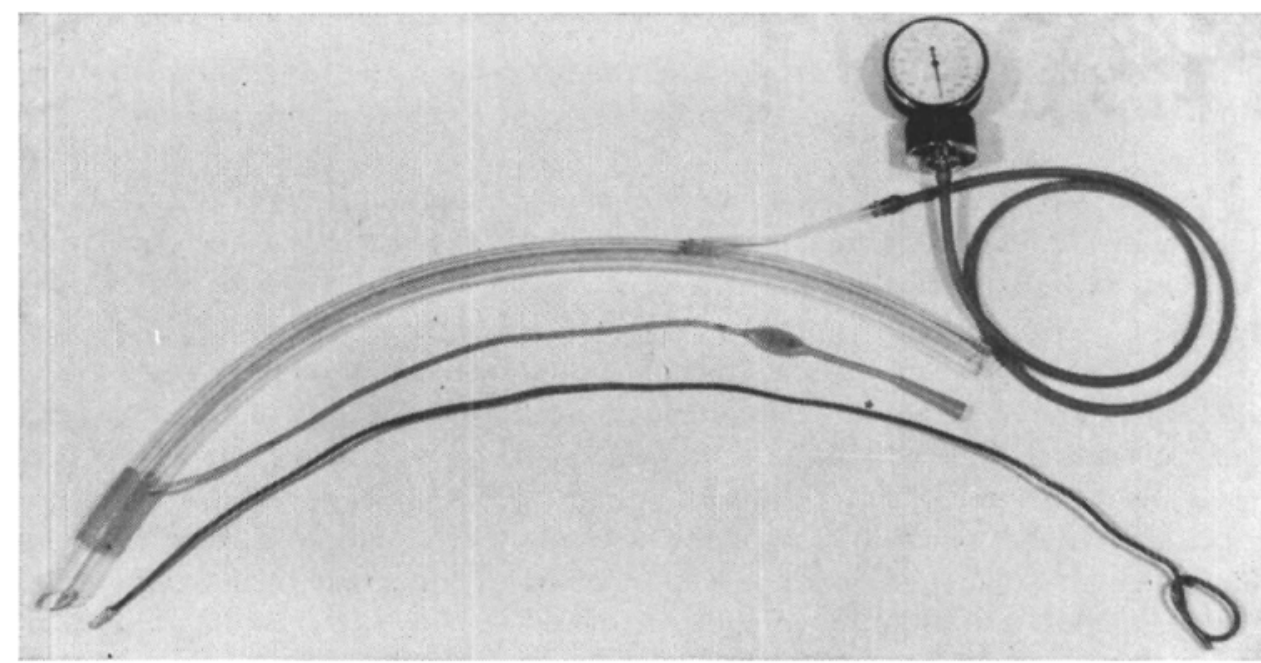

FIGUne 2. Cuffed endotracheal tube with pressure gauge and wire obturator.

Once the chest is opened the respirator pressure must be adjusted to maintain the optimum $15-18 \mathrm{~mm}$. $\mathrm{Hg}$ airway pressure. During bypass, ventilation is maintained at pressures or 10-12 mm. Hg. Periodic deep breaths are administered by hand every 15 to 20 minutes throughout the anaesthetic, using the respirator bag in the inspiratory line. 


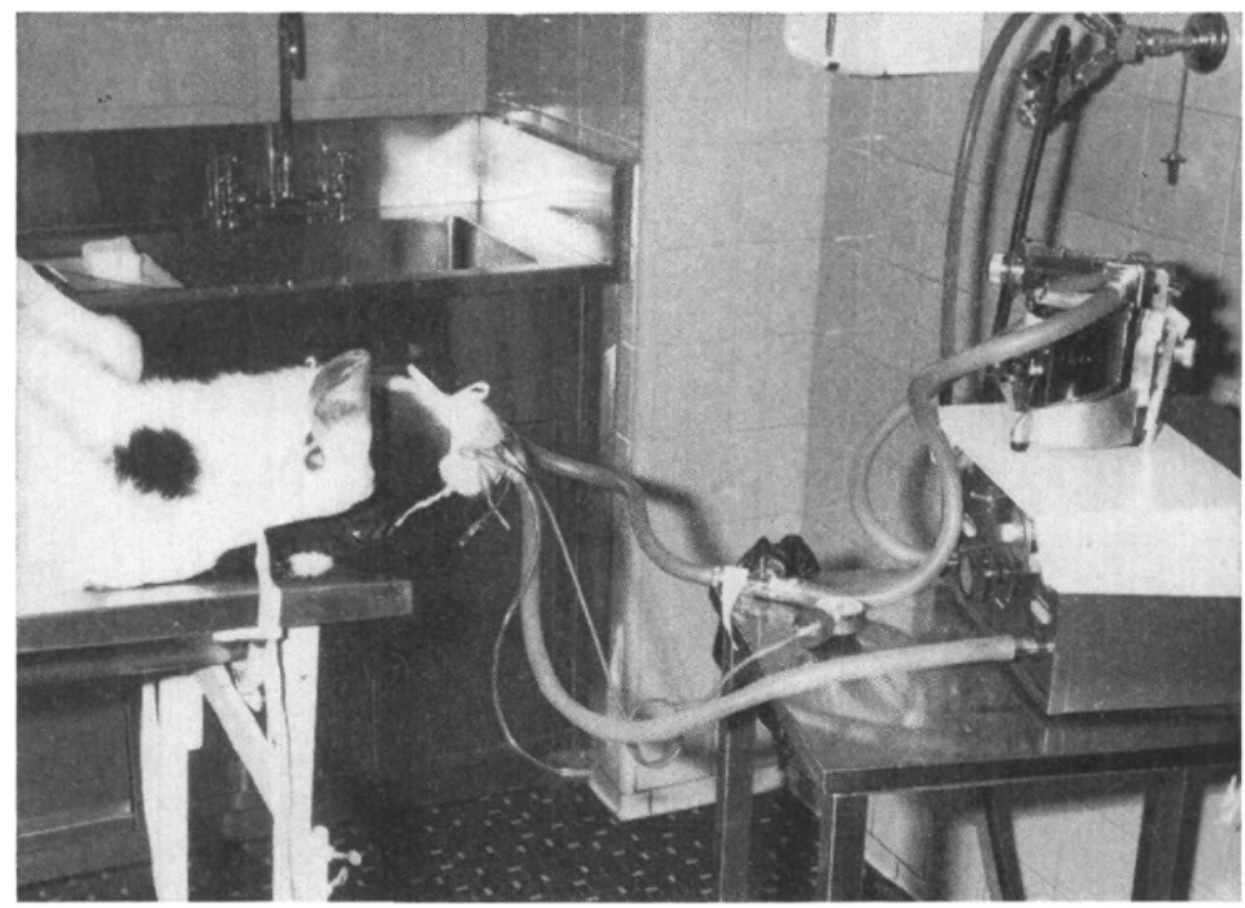

Figure 3. Respirator with Pentec in intake line. Note the bag in inspiratory line and the gastric tube in place.

Animals are perfused at $30^{\circ} \mathrm{C}$, and the oxygen for the oxygenator is passed through the Pentec to deliver 0.2 to 0.4 per cent levels of Penthrane during the bypass.

At completion of the bypass the animal is carried at the lowest anaesthetic level which prevents spontaneous movement, usually 0.2 to 0.3 per cent. Some animals require no further anaesthetic if closure can be achieved within one hour.

Postoperatively the animals are maintained on room air through a Mörch Piston Respirator for 30 to 60 minutes until fully awake.

Extubation is carried out after tracheobronchial suctioning when adequate spontaneous respirations are exhibited.

Arterial blood pressure is monitored via a carotid artery catheter using a Statham strain gauge. Central venous pressure is measured by jugular venous catheterization and an adapted spinal manometer. The electrocardiagram is followed during the induction and postoperatively if indicated. After removal of the catheters one and a half to two hours postoperatively the skin is sutured without anaesthesia.

\section{Results}

Our series is comprised of 25 calves; 10 male and 15 female, ranging in weight from 40 to $80 \mathrm{~kg}$. and in age from three weeks to three months. The duration of 
anaesthesia has varied from six to twelve hours and bypass time has ranged from one and a half to four hours. In this group only one death could be directly attributed to anaesthesia. This animal succumbed during induction with 1.5 per cent methoxyflurane prior to pressure and E.C.G. monitoring.

Serial arterial blood gas measurements before, during, and after bypass have demonstrated adequate oxygenation in all cases. The respiratory alkalosis present while the animal is on the pump tends to revert towards normal within a few minutes of discontinuing bypass.

\section{Discussion}

In complex experimental situations such as cardiopulmonary bypass in calves it is essential to simplify as many facets of the procedure as possible. The need for a simple scheme of anaesthesia, which could be administered safely and without constant supervision by an anaesthetist, prompted the development of the method described.

Succinylcholine chloride in the suggested dose produces a complete but transient depolarization block of the neuromuscular end-plate in all voluntary muscles within five minutes. Although total paralysis in the conscious animal appears cruel, it is felt to be more humanitarian than restraint during induction in large powerful animals. We have found the calves extremely sensitive to succinylcholine chloride and during our early experience noted prolonged periods of apnoea and signs of a curare-like response in two animals. One-fifth of the human dose by weight was subsequently found to be adequate for intubation, and no further signs of overdosage have been apparent.

Methoxyflurane, a halogenated hydrocarbon anaesthetic agent, was chosen because of its wide safety and slow induction which, with cautious administration, reduces the possibility of overdosage. ${ }^{3}$ During the early phase of induction it is important to observe the calf carefully for signs of cardiac depression. Occasionally, marked bradycardias occurred, and for this reason E.C.G. monitoring is suggested during induction. If arterial pressure readings or E.C.G. changes suggest circulatory depression, the anaesthetic agent must be discontinued temporarily. If no immediate improvement is noted, a peripheral vasoconstrictor, methoxamine hydrochloride (Vasoxyl), may be given slowly, 10-20 mg. intravenously, diluted to 10 c.c. with normal saline. With no further improvement dilute epinephrine may be given by slow intravenous drip for temporary support ( 1 c.c. of 1:1000 in 150 c.c. 5 per cent G/W). ${ }^{4}$ Systolic pressure must be maintained above $80 \mathrm{~mm}$. $\mathrm{Hg}$ in this way both before and after bypass.

Vasoxyl is chosen for its potential to reverse the peripheral vasodilatation seen in anaesthetic overdosage. If immediate improvement is not seen, decreased myocardial contractility is felt to be present in addition to decreased peripheral resistance. This myocardial depression has been reversed in two animals prior to bypass, using dilute epinephrine as described. Although a danger of cardiac arrhythmias is said to exist, ${ }^{5}$ we have not observed such toxic effects in combining epinephrine with methoxyflurane either for severe myocardial depression or in the resuscitation period when indicated immediately following bypass. 
Although the Pentec vaporizer was not designed for use in the inspiratory line, the simple equipment described has given us excellent results. The use of the standard laboratory respirator simplifies the technique sufficiently to outweigh the advantages of using a rebreathing bag and flow-meter system with the Pentec proximal to the respirator.

The time required for induction has varied, and in some of the larger animals a short period of hyperventilation (20-25 breaths/minute) has been found necessary to produce satisfactory levels of anaesthesia.

A reduction in ventilatory pressure during bypass has been found necessary to prevent movement of the operative site, but partial inflation of the lungs during this period is essential. The simple adjustment of the respiratory pressure is the most convenient way to achieve both of these objectives. A respirator bag has been inserted into the inspiratory line to expand the lungs fully by manual operation every 15 to 20 minutes throughout the entire operation. These techniques minimize postoperative atelectasis by maintaining aeration of peripheral bronchioles and alveoli, and keeping pulmonary compliance in the normal range. ${ }^{0}$

Continuous airway pressure monitoring has prevented overexpansion of the lungs and the attendant risks of interference with venous return and damage to the fragile alveoli of these young animals.

In the immediate postoperative period the Mörch respirator is used to maintain complete expansion of the lungs as spontaneous respirations return. The use of room air in the system allows adaptation from 100 to 20 per cent oxygen, enhancing the accumulation of carbon dioxide and speeding the return of normal respiratory drive.

The need for postoperative analgesia or sedation is obviated by the long period of washout required for methoxyflurane. ${ }^{3}$ Suturing of the neck incision is carried out painlessly in the early postoperative period. The animals are quiet and apparently comfortable during this phase; thus restraint has seldom been required.

\section{SUMMARY}

A safe and convenient method of anaesthesia, utilizing standard laboratory apparatus, has been described for use in cardiopulmonary bypass procedures in calves. The technique evolved during early work on aortic valve xenograft replacements. The long-term results of the series will be reported in a subsequent publication.

\section{ACKNOWLEDGMENTS}

The authors wish to express their gratitude for the technical assistance of Mr. Roger Samson and the co-operation of the Canada Packers Limited.

\section{RÉSUMÉ}

Pour plusieurs raisons, le veau est l'animal de choix pour les expériences sur la chirurgie cardiovasculaire. Les auteurs décrivent en détail l'évolution de la technique d'anesthésie par inhalation au cours de 25 cas de remplacements de valves 
aortiques pratiques ces dernières années. On préfère le méthoxyflurane (Penthrane) pour sa marge de sécurité et ses propriétés d'induction lente. En n'utilisant que le matériel de laboratoire standard, on a trouvé sûre et efficace la technique décrite. Dans cette série d'expériences, une seule mort a été attribuée directement à l'anesthésie.

\section{REFERENCES}

1. Larson, R. E.; Mofritr, E. A.; \& McGoon, D. C. Experimental Surgery in Calves. Anaesthesia. 3: 101 (1963).

2. Wrucri, J. G. \& HAir, L. W. Veterinary Anaesthesia and Analgesia. 5th ed. London: Balliere Tindall and Cox (1961).

3. Tombiv, P. J. Methoxyflurane. Brit.J. Anaesth. 37 : 706 (1965).

4. Goldberg, L. I.; Bloodwell, R. D.; Braunwald, E.; \& Morhow, A. G. The Direct Effects of Norepinephrine, Epinephrine and Methoxamine on Myocardial Contractile Force in Man. Circulation. 22: 1125 (1960).

5. Bamforth, B. J.; SIRBEcker, K. L.; KraEMger, R.; \& Orth, O. S. Effect of Epinephrine on the Dog Heart during Methoxyflurane Anaesthesia. Anaesthesiology. 22: 169 (1961).

6. EcBerRT, L. D.; LAver, M. B.; \& BendoxeN, H. H. Intermittent Deep Breaths and Compliance during Anaesthesia in Man. Anaesthesiology. 24: 57 (1963).

CANADIAN STANDARD FOR ENDOTRACHEAL TUBES AND ADAPTORS

A Canadian standard on endotracheal tube connectors and adaptors is now available.

"Standard Z168.2 Endotracheal Tube Connectors and Adaptors" may be obtained from the Canadian Standards Association, 235 Montreal Road, Ottawa 7, Ontario.

Price: $\$ 1.25$ each 